\title{
Tetrabenazine-induced oculogyric crisis - a rare complication in the treatment of Gilles de la Tourette syndrome
}

This article was published in the following Dove Press journal:

Neuropsychiatric Disease and Treatment

25 February 2016

Number of times this article has been viewed

\author{
Piotr Janik' \\ Monika Figura ${ }^{1,2}$ \\ 'Department of Neurology, \\ Anna Gostynska Wolski Hospital, \\ 2Department of Neurology, Faculty \\ of Health Sciences, Medical University \\ of Warsaw, Warsaw, Poland
}

\begin{abstract}
Tetrabenazine is used in the treatment of chorea, tardive dyskinesia, tics, and dystonia. It rarely causes acute eyeball dystonia and the description of this complication in Gilles de la Tourette syndrome is limited. We provide a description of an acute oculogyric crisis caused by tetrabenazine in a patient with severe tics. The patient had never developed acute dystonic reactions, although he was previously exposed to numerous dopamine receptor-blocking agents. After 8 days of therapy with tetrabenazine at a dose of $62.5 \mathrm{mg}$ daily, the patient developed involuntary movement of the eyeballs. Withdrawal of tetrabenazine caused resolution of all symptoms after a week. The purpose of this description is to draw attention to the potential of tetrabenazine to induce acute oculogyric crisis as well as the difficulty of differentiating druginduced dystonia from dystonic tics in patients with Gilles de la Tourette syndrome.

Keywords: acute dyskinesia, dystonic tics, eyeball dystonia, drug-induced dystonia, tic disorder, tetrabenazine-induced side effects
\end{abstract}

\section{Introduction}

Oculogyric crisis (OGC), classified as eyeball dystonia, was first described in patients suffering from encephalitis lethargica. ${ }^{1}$ Nowadays, this symptom is more frequently observed as a side effect of treatment with dopamine receptor-blocking drugs (DRBDs). ${ }^{2}$ It manifests as spasmodic deviations of the eyeballs, mainly upward but also in other directions, lasting from a few minutes to several hours. ${ }^{3}$ It occurs during the first hours or days after the introduction of DRBDs.

Tetrabenazine is mainly used in patients with hyperkinetic movement disorders, such as tics, chorea, tardive dyskinesia, and dystonia. Its mechanism of action involves the reversible inhibition of vesicular monoamine transporter type 2 , thus preventing the uptake of serotonin, norepinephrine, and dopamine by presynaptic neurons. Acute dystonia is a rarely encountered side effect of tetrabenazine treatment. Jankovic and Beach found that acute dystonic reactions occurred in nine $(2.3 \%)$ patients and two $(0.5 \%)$ additional patients had acute oculogyric crises attributed to tetrabenazine. ${ }^{4} \mathrm{We}$ present a case report of a patient suffering from Gilles de la Tourette syndrome (GTS) who developed OGC during treatment with tetrabenazine.

\section{Case report}

An 18-year-old male patient with GTS began to experience head shaking followed by coughing at the age of 11 years. During the next several years, he developed numerous motor and vocal tics (nose twitching, jaw tightening, biting his cheek, clenching his fingers into a fist, throwing his head back, rolling his eyes to one side, tensing his

\footnotetext{
Correspondence: Piotr Janik

Department of Neurology, Anna Gostynska Wolski Hospital, Kasprzaka I7, 01-2I I Warsaw, Poland Tel +48223894766 Email piotr.janik@wum.edu.pl
} 
buttocks, twisting movements of the hands and feet, resulting in abnormal posture, bending his body to one side giving the sustained position of his body, and exhaling loudly). His tic-reducing therapy included haloperidol, perphenazine, quetiapine, sulpiride, and clonazepam without success, and thus he was referred to Piotr Janik (the first author of this paper) at age 17 years. Pregnancy, perinatal period, and developmental milestones during infancy were normal. He had a positive family history of tics (his brother) and obsessive-compulsive behaviors on his paternal side (his brother, uncle, and grandfather). We found his tics to be associated with lower educational achievements and negative impacts on his family and social life. During the next year, he was put one by one on risperidone, aripiprazole, and topiramate without success.

During another visit at age 18 years, he presented with jaw snaps, head jerks, quickly flexing and extending arms, popping knuckles, tensing of the abdomen, nose picking, rubbing one foot against the other, bending up of the nose using a finger combined with frowning, and rapid jerking of the body. His vocal tics included screeching; throat clearing; and sniffing, humming, and squeaking noises. He also displayed self-injurious behavior - he had to use a mouthguard to protect his teeth from damage caused by clenching his jaw. To assess the severity of his tics, the Yale Global Tic Severity Scale (YGTSS) was used. His Total Tic Severity Score was rated as 36 and Impairment 40. Comorbid conditions included depression at age 16 treated with escitalopram and paroxetine. At the time of examination, no comorbid mental disorders were diagnosed. Due to the lack of effectiveness of previous treatments, tetrabenazine in gradually increasing dose was introduced. However, after 8 days of therapy, at a dose of $62.5 \mathrm{mg}$ of tetrabenazine daily, the patient developed involuntary movements of the eyeballs characterized by spasmodic deviations of the eyes upward and to one side that lasted for around an hour, with a frequency of a few times per day. OGC was mostly triggered by bright light. In addition to OGC, the patient experienced severe, brief episodes of throwing back his head and twisting movements of his hands and feet that resembled retrocollis and limb dystonia, respectively. Excessive salivation, slurred speech, and food dropping from the mouth were also reported by the patient. All symptoms resolved a week after tapering the tetrabenazine dose to $37.5 \mathrm{mg}$ daily. At this dose, tics remained poorly controlled and tetrabenazine was totally stopped. Despite further treatment with other DRBDs, among them tiapride, ziprasidone, olanzapine, and haloperidol, OGC never reoccurred. Permission from an ethics committee was not necessary in the presented case, as tetrabenazine is a widely approved treatment for GTS. The drug has previously been used as a last-resort treatment for patients with severe tics; therefore, no novel medical treatments were performed on our patient. The patient's personal data has not been revealed in this article. The patient provided written informed consent.

\section{Discussion}

Acute OGC seems to be a rare complication in the treatment of GTS patients because, nowadays, mostly second-generation DRBDs are used to alleviate tics. There are only a few case reports in the literature of this complication arising with the use of second-generation DRBDs. Two papers report the development of acute OGC shortly after administration of aripiprazole and one paper reports similar symptoms after treatment with risperidone..$^{5-7}$ We also observed two young adults with GTS who developed OGC after treatment with risperidone $4 \mathrm{mg}$ daily and sulpiride $300 \mathrm{mg}$ daily.

The only two reports of tetrabenazine-induced acute dystonia were those of Jankovic and Beach ${ }^{4}$ and Burke et al. ${ }^{8}$ The four patients described by Burke et al varied in terms of drug dose (from 25 to $300 \mathrm{mg}$ ), underlying condition (GTS in one case, dystonia in three others), patients' age (from 20 to 30 years), and sex (two females, two males). ${ }^{8}$ Unfortunately, the characteristics of patients who developed acute dystonia with tetrabenazine treatment were not included in the second paper. ${ }^{4}$ Both authors reported that acute dystonia was dose-related and improved spontaneously when the dosage was reduced, as was the case with our patient. In contrast to Burke's patient with GTS who developed OGC and retrocollis while being treated with tetrabenazine $300 \mathrm{mg}$, we observed such a complication on a low dose of tetrabenazine. The fact that tetrabenazine-induced OGC is rarely seen and may occur with different doses suggests that this complication will develop in vulnerable young adults in particular.

In addition, our patient had some dystonic tics as part of his tic repertoire since early adolescence. Interestingly, these tics as well as some facial and cervical motor tics worsened during treatment with tetrabenazine. The severity of all these tics abated after tetrabenazine treatment was reduced and then stopped. Since dystonic tics often resemble acute dystonic reaction, it is not always easy to differentiate these movement disorders. Compared to dystonia, tics are shorter lasting movements, typically not painful, are preceded by premonitory sensations, and do not cause persistent postures. Based on these clues, we classified these movements as worsened tics rather than drug-induced acute dystonic reaction. 
The pathogenesis of medication-induced acute dystonia has not been fully elucidated. It is believed that to cause acute dystonic reactions, the drug must be able to block dopamine receptors. However, tetrabenazine, a monoaminedepleting medication, and alpha-methyl-para-tyrosine, a catecholamine-depleting agent, may induce acute dystonic reactions. ${ }^{89}$ Our case report is not in line with the hypothesis that tetrabenazine causes this side effect by dopamine blockade rather than monoamine depletion because it is also able to block dopamine receptors in rat brain. ${ }^{10,11}$ Our patient had been exposed to numerous DRBDs before and after he developed OGC, which never caused symptoms of acute dystonia.

The resolution of OGC after a reduction in the dosage of tetrabenazine, which probably resulted in enhanced dopaminergic transmission, is compatible with the theory that the decrease of dopamine transmission induced by tetrabenazine could also be involved in the pathogenesis of acute dystonia.

\section{Acknowledgment}

The authors gratefully acknowledge the assistance of Adam Cholinski in drafting and editing the manuscript.

\section{Disclosure}

The authors report no conflicts of interest in this work.

\section{References}

1. Berger J, Vilensky J. Encephalitis lethargica (von Economo's encephalitis). Handb Clin Neurol. 2013;123:745-761.

2. Dorevitch A. Neuroleptics as causes of oculogyric crises. Arch Neurol. 1984;41(1):15-16.

3. Ayd FJ. A survey of drug-induced extrapyramidal reactions. JAMA. 1961;175(12):1054-1060.

4. Jankovic J, Beach J. Long-term effects of tetrabenazine in hyperkinetic movement disorders. Neurology. 1997;48(2):358-362.

5. Rizzo R, Gulisano M, Calì PV. Oculogyric crisis: a rare extrapyramidal side effect in the treatment of Tourette syndrome. Eur Child Adolesc Psychiatry. 2012;10(21):591-592.

6. Fountoulakis KN, Siamouli M, Kantartzis S, Panagiotidis P, Iacovides A, St Kaprinis G. Acute dystonia with low-dosage aripiprazole in Tourette's disorder. Ann Pharmacother. 2006;40(4):775-777.

7. Masliyah T, Ad-Dab'bagh Y. Low-Dose Risperidone-Induced oculogyric crises in an adolescent male with autism, Tourette's and developmental delay. J Can Acad Child Adolesc Psychiatry. 2011;20(3):214-216.

8. Burke RE, Reches A, Traub MM, Ilson J, Swash M, Fahn S. Tetrabenazine induces acute dystonic reactions. Ann Neurol. 1985;17(2): 200-202.

9. McCann UD, Penetar DM, Belenky G. Acute dystonic reaction in normal humans caused by catecholamine depletion. Clin Neuropharmacol. 1990;13(6):565-568.

10. Reches A, Burke RE, Kuhn CM, Hassan MN, Jackson VR, Fahn S. Tetrabenazine, an amine-depleting drug, also blocks dopamine receptors in rat brain. J Pharmacol Exp Ther. 1983;225(3):515-521.

11. Cronin MJ, MacLeod RM. Tetrabenazine has properties of a dopamine receptor antagonist. Ann Neurol. 1982;12(3):257-262.
Neuropsychiatric Disease and Treatment

\section{Publish your work in this journal}

Neuropsychiatric Disease and Treatment is an international, peerreviewed journal of clinical therapeutics and pharmacology focusing on concise rapid reporting of clinical or pre-clinical studies on a range of neuropsychiatric and neurological disorders. This journal is indexed on PubMed Central, the 'PsycINFO' database and CAS,

\section{Dovepress}

and is the official journal of The International Neuropsychiatric Association (INA). The manuscript management system is completely online and includes a very quick and fair peer-review system, which is all easy to use. Visit http://www.dovepress.com/testimonials.php to read real quotes from published authors. 